\title{
Evaluation outcomes of a long-running adult nutrition education programme
}

\author{
Simone Pettigrew ${ }^{1, *}$, Sarah Moore ${ }^{2}$, lain S Pratt ${ }^{2}$ and Michelle Jongenelis ${ }^{1}$ \\ ${ }^{1}$ School of Psychology and Speech Pathology, Curtin University, GPO Box U1987, Perth, WA 6845, Australia: \\ ${ }^{2}$ Cancer Council Western Australia, Perth, Australia
}

Submitted 14 November 2014: Final revision received 6 April 2015: Accepted 10 April 2015: First published online 20 May 2015

\begin{abstract}
Objective: For more than 20 years, the FOODcents adult nutrition education programme has been delivered to Western Australians. The aim of the programme is to provide disadvantaged individuals with the knowledge, skills and motivation to buy healthy foods on a limited budget. The present study evaluated whether the FOODcents curriculum and the way it is delivered are effective in improving participants' nutrition-related knowledge and behaviours.

Design: Evaluation data were collected via in-session pre-post questionnaires and a post-course online questionnaire.

Setting: Western Australia.

Subjects: Data were collected from participants attending just over one-half (54\%) of the FOODcents courses conducted over the two-year evaluation period. In total, 927 course participants provided usable data.

Results: After exposure to the course, respondents demonstrated an improved ability to: (i) categorize foods according to the frequency with which they should be consumed and the proportion of the food budget that should be allocated to them; (ii) correctly interpret nutrition labels on food products; and (iii) appreciate the link between diet/obesity and a range of diseases. Improvements in the latter were especially pronounced among participants of low socio-economic status. In terms of behaviour change, significant improvements in fruit and vegetable consumption were reported, along with reductions in the consumption of fast food. Participants of low socio-economic status reported the greatest changes.

Conclusions: The results indicate that the FOODcents nutrition education programme improves participants' nutrition-related knowledge and behaviours.
\end{abstract}

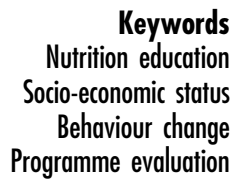

Nutrition education is an intervention strategy that can be used by governments and non-government organizations (NGO) in their attempts to prevent and/or treat obesity $^{(1,2)}$. The $\mathrm{WHO}^{(3)}$ Global Action Plan for the Prevention and Control of NCDs [non-communicable diseases] 2013-2020 recognizes the importance of this strategy in its recommendation for nation states to 'Create health- and nutrition-promoting environments, including through nutrition education'. Similarly, the World Cancer Research Fund's NOURISHING framework ${ }^{(1)}$ and the Obesity Policy Action framework ${ }^{(4)}$ emphasize the need to provide the levels of nutrition education necessary to enable individuals to make healthy food choices. However, nutrition education is just one dietary approach to obesity prevention that is ideally complemented with population-level strategies such as healthy eating campaigns and food labelling policies ${ }^{(2)}$. The need for a broad range of strategies reflects the multifactorial nature of obesity and the need to adopt multiple approaches to address its complex aetiology ${ }^{(5)}$.

Nutrition education interventions are typically targeted at disadvantaged groups, such as those of lower socioeconomic status (SES) ${ }^{(6,7)}$. This emphasis is appropriate given that low SES is associated with higher levels of overweight and obesity and resulting weight-related illnesses ${ }^{(8,9)}$. However, relatively few nutrition education programmes and interventions have been rigorously evaluated, especially in terms of their ability to improve outcomes for low-SES individuals ${ }^{(10)}$. A notable exception is the long-running US Expanded Food and Nutrition Education Program (EFNEP). In operation since 1969, EFNEP involves the delivery of group nutrition education classes to participants with limited financial resources over six to twelve sessions that focus on food budgeting, food safety and diet quality ${ }^{(11,12)}$. Over the years, various studies have demonstrated that EFNEP improves 
participants' nutrition knowledge and self-reported food practices relating to food budgeting, food hygiene and meal preparation $^{(13-16)}$. In addition, analyses indicate that the programme is likely to be cost-effective, with results suggesting that the estimated benefits to individuals and society more than offset the costs of programme delivery ${ }^{(17,18)}$.

Some short-term interventions have also been evaluated. These interventions have tended to focus on food budgeting and/or general nutrition education delivered over one to six sessions ${ }^{(7,19-21)}$. The results of these intervention studies support the conclusion that the provision of nutrition information in group settings has the potential to improve disadvantaged adults' food-related knowledge, attitudes, confidence and self-reported food intake. They also suggest that programmes involving a smaller number of sessions than those offered in EFNEP may be effective, but there is a lack of data relating to sustained programmes (rather than intervention studies) targeting low-SES groups that offer nutrition education over a smaller number of sessions.

FOODcents is a long-standing nutrition education programme delivered to disadvantaged groups in Western Australia. It is a community-based programme that features face-to-face information sessions that can include skills training components such as cooking classes and guided supermarket tours. The programme commenced in 1992 as a pilot project in regional (country) Western Australia and was subsequently implemented state-wide in $1995^{(22)}$. An initial programme evaluation was undertaken about five years after the commencement of the programme to assess its ability to meet disadvantaged individuals' nutrition education needs ${ }^{(23)}$. The evaluation results indicated that the content and delivery method of FOODcents was effective in meeting programme objectives, thereby justifying continued funding by the Western Australian Department of Health.

The purpose of the present study is to re-evaluate FOODcents to assess whether it continues to provide relevant information to lower-SES individuals and whether knowledge improvements and skills acquisition are resulting in behaviour change. A re-evaluation is needed at this time given increasing rates of obesity in Australia and the ongoing need to identify effective policy responses. Almost two-thirds (63\%) of Australian adults are now classified as overweight or obese compared with $56 \%$ in $1995^{(8)}$. There is thus an urgent need for information relating to the kinds of nutrition education programmes that can favourably influence individuals' diets to add to the limited evidence base about this form of health promotion ${ }^{(1)}$. In particular, data are needed relating to the effectiveness of shorter courses relative to longer courses to assist policy makers determine optimal levels of service provision.

\section{About FOODcents}

For more than 20 years, FOODcents has been providing Western Australians with nutrition education sessions relating to improving their household food expenditure according to the healthy eating pyramid ${ }^{(24)}$. This involves advising participants on how to increase their consumption of fruit, vegetables and cereals, and reduce their consumption of foods high in salt, fat and/or sugar. As in other countries, those of lower SES in Australia have higher than average intakes of unhealthy foods and lower than average intakes of fruits and vegetables ${ }^{(25-28)}$. The FOODcents curriculum specifically addresses these consumption behaviours that are associated with risk of chronic disease ${ }^{(29,30)}$.

The FOODcents curriculum was developed according to the principles of the Precede-Proceed programme planning model ${ }^{(31)}$, which highlights the need to work with target groups to identify knowledge gaps and other barriers to engaging in recommended behaviours and then develop content that addresses the gaps and barriers. Accordingly, initial formative research identified the ability to appropriately manage a limited food budget and basic cooking skills as the primary factors preventing lower-SES individuals from achieving a healthy diet. Similar issues have been identified with disadvantaged groups in other countries $^{(32)}$. These knowledge and skill deficits became the core of the FOODcents curriculum ${ }^{(23)}$ and today the programme remains focused on these elements, with an added emphasis on understanding the diet-disease link and using food labelling to achieve a healthy diet.

Consistent with the recommendation for nutrition education interventions to be behaviourally focused to maximize effectiveness ${ }^{(33,34)}$, there is extensive use of in-session activities designed to actively engage participants with the course content. An example of an activity relates to the healthy food pyramid. The instructor supplies food packets (processed foods) and pictures of fresh foods (fruits and vegetables) for participants to classify. Tape is used to outline the segmented healthy eating pyramid on the floor and participants place the packets/pictures where they think they belong. Guided discussion with the group results in items being progressively moved until all items are in their correct locations.

FOODcents is delivered via a collaborative arrangement involving three NGO: the Cancer Council Western Australia, the Australian Red Cross and Foodbank WA. Although each organization has a somewhat different organizational mission, they are united in their objective to improve the health of Western Australians, especially of the disadvantaged. By working together to deliver FOODcents courses, the three NGO are able to access a broad range of client groups and cover the very large geographical area of Western Australia. Two types of courses are offered: (i) participants can elect to attend a single-session course of $1-2 \mathrm{~h}$ duration that primarily focuses on a specific issue (e.g. the healthy eating pyramid or food labelling); or (ii) they can enrol in a multi-session course that involves up to eight sessions and covers a broader range of nutrition topics. The content and pace of 
delivery are modified for the literacy needs of each group, including accommodating the presence of a translator for immigrant participants or assistants for disabled participants.

Approximately 2500 Western Australians attend a FOODcents course each year, including Indigenous and new (immigrant) Australians and those residing in temporary/sheltered housing. While the primary focus is on those with limited incomes, the programme is inclusive and any interested person can register to attend a course. However, relatively few participants are of high SES and the course content is specifically designed to cater for those with low levels of nutrition literacy. Sessions are delivered at various community-based locations throughout the metropolitan area and in major regional centres. Examples of venues include town halls, church halls, community centres and shopping centre facilities. In addition, each of the three participating NGO has meeting rooms that are used to host sessions. In the case of multiple-session courses, almost all are conducted on a weekly basis, although they can also be run on consecutive days. Both session spacing and session duration are determined by the needs and preferences of participant groups.

\section{Method}

Given the focus of the FOODcents programme on the delivery of nutrition information to disadvantaged groups, multiple instruments were developed and utilized during the evaluation process to accommodate the literacy needs of the participants as much as possible while maximizing the rigour of data collection and analysis ${ }^{(34)}$. The instruments, described below, were developed in consultation with members of the three organizations involved in programme delivery and pilot tested with ninety course participants prior to formal implementation. Only minor wording changes were required as a result of the pilot testing process. The protocol received approval from the University of Western Australia Human Ethics Committee and the evaluation was conducted over two years between June 2012 and May 2014.

\section{Instruments}

Strong evaluation design includes assessments at both preand post-intervention time points ${ }^{(34)}$. To achieve this, hard-copy questionnaires were administered at the commencement and conclusion of a sample of courses to assess participants' pre- and post-session nutrition knowledge and behaviour. Given the need to keep the instruments to a length that was both manageable for participants and feasible within the time frame of course delivery, multiple versions were developed. Reflecting the flexible nature of programme delivery, seven different pre-post in-session questionnaires were developed to ensure the instruments were suitable in content and length for the different courses and participant groups. In addition, an online questionnaire was administered to those participants who provided an email address and gave permission to be contacted again at a later date. Table 1 provides a summary of the instruments and their topic coverage.

\section{In-session surveys}

Two longer questionnaires were designed for groups comprised of more literate participants and/or those individuals attending multiple-session courses that covered a more extensive nutrition curriculum and permitted greater time for questionnaire completion. The first

Table 1 Survey instruments

\begin{tabular}{|c|c|c|}
\hline Instrument & Main topics covered & $\begin{array}{l}\text { Time in } \\
\text { field }\end{array}$ \\
\hline $\begin{array}{l}\text { Long survey, } \\
\text { version } 1\end{array}$ & $\begin{array}{l}\text { - Perceived usefulness of course } \\
\text { - Confidence to buy healthy foods on } \\
\text { a budget } \\
\text { - Food budgeting - proportions } \\
\text { of budget } \\
\text { - Food label reading } \\
\text { - Diet-disease link } \\
\text { - Healthy eating pyramid } \\
\text { - F\&V and fast-food consumption } \\
\text { - Demographics }\end{array}$ & Year 1 \\
\hline $\begin{array}{l}\text { Long survey, } \\
\text { version } 2\end{array}$ & $\begin{array}{l}\text { - Perceived usefulness of course } \\
\text { - Confidence to buy healthy foods on } \\
\text { a budget } \\
\text { - Food budgeting - price per } \\
\text { kilo method } \\
\text { - Healthy eating pyramid } \\
\text { - Food hygiene } \\
\text { - F\&V and fast-food consumption } \\
\text { - Demographics }\end{array}$ & Year 2 \\
\hline $\begin{array}{c}\text { Short survey, } \\
\text { version } 1\end{array}$ & $\begin{array}{l}\text { - Perceived usefulness of course } \\
\text { - Food budgeting } \\
\text { - Demographics }\end{array}$ & $\begin{array}{r}\text { Years } 1 \\
\text { and } 2\end{array}$ \\
\hline $\begin{array}{l}\text { Short survey, } \\
\text { version } 2\end{array}$ & $\begin{array}{l}\text { - Perceived usefulness of course } \\
\text { - Food label reading } \\
\text { - Demographics }\end{array}$ & $\begin{array}{r}\text { Years } 1 \\
\text { and } 2\end{array}$ \\
\hline $\begin{array}{c}\text { Short survey, } \\
\text { version } 3\end{array}$ & $\begin{array}{l}\text { - Perceived usefulness of course } \\
\text { - Diet-disease link } \\
\text { - Demographics }\end{array}$ & $\begin{array}{r}\text { Years } 1 \\
\text { and } 2\end{array}$ \\
\hline $\begin{array}{l}\text { Short survey, } \\
\text { version } 4\end{array}$ & $\begin{array}{l}\text { - Perceived usefulness of course } \\
\text { - Healthy eating pyramid } \\
\text { - Confidence to buy healthy foods on } \\
\text { a budget } \\
\text { - Demographics }\end{array}$ & $\begin{array}{r}\text { Years } 1 \\
\text { and } 2\end{array}$ \\
\hline Online survey & $\begin{array}{l}\text { - Perceived usefulness of course } \\
\text { - Consumption of a range of foods } \\
\text { including fruits, vegetables, fast food, } \\
\text { cereals, legumes, sodas, cookies/ } \\
\text { cakes and low-salt options } \\
\text { - Shopping behaviours such as reading } \\
\text { food labels and using the price per } \\
\text { kilo method } \\
\text { - Demographics }\end{array}$ & $\begin{array}{r}\text { Years } 1 \\
\text { and } 2\end{array}$ \\
\hline
\end{tabular}

F\&V, fruit and vegetables. 
long questionnaire was administered over the first year of the evaluation period and the second long version was administered over the second year. Both instruments featured the same series of demographic questions and items relating to general perceptions of the FOODcents programme, but had some different items to assess nutrition knowledge. Utilizing two versions of the instrument that covered different elements of the FOODcents curriculum permitted assessment of participants' understanding of a broader range of nutrition information over the evaluation period than could have been assessed with a single instrument. Only one version of the long questionnaires was in the field at any point in time.

In addition, four short questionnaires were developed that dealt with a smaller number of curriculum elements. These instruments focused on food budgeting, food label reading, the diet-disease link and the healthy eating pyramid, with the relevant items being the same as those in the longer instruments. The shorter instruments were better suited to the individual (single) sessions that were briefer in duration and hence covered fewer curriculum elements and allowed less time for survey administration. They were also more appropriate for participants with lower literacy levels in multi-session courses because of the reduced respondent burden ${ }^{(34)}$. In these instances, the short instruments most relevant to the curriculum covered in the multi-session courses were selected for administration. The appropriate instrument to use was determined either before the session (e.g. representatives from multicultural groups organizing sessions for their members often provided information about literacy levels at the time of course booking) or after initial in-session ice-breakers that permitted some assessment of the communication abilities of participants. For practical reasons, all members of each group received the same questionnaire, which was administered by the FOODcents instructor delivering the course.

\section{Online post-session survey}

An online follow-up survey was administered on average approximately six weeks after course attendance. This survey gathered additional data relating to participants' subsequent use of the information covered in the course. In this survey, respondents were asked to report various nutrition-related behaviours, such as their consumption of wholemeal products, modification of recipes to make them healthier and reduction of salt intake.

\section{Statistical analyses}

Equivalent items were pooled across the instruments for analyses. Pre- to post-course changes in participants' perceived confidence to purchase healthy foods on a budget and their dietary behaviours were assessed via paired-samples $t$ tests. Improvement in nutrition knowledge over time was assessed via paired-samples $t$ tests (where data were interval in nature) or Pearson $\chi^{2}$ tests (where data were categorical). SES differences in improvement in nutrition knowledge and dietary behaviours were assessed via one-way ANOVA (for interval data) or Pearson $\chi^{2}$ tests (for categorical data). Post hoc analyses (Fisher's LSD (least significant difference) or adjusted standardized residuals) were conducted where relevant. A $P$ value of $<0.05$ was used as the significance cut-off. Bonferroni-adjusted $\alpha$ levels were used to control for the family-wise error rate where relevant. As the proportion of missing values on all items administered was less than 5\%, an available-case analysis approach was used in which incomplete cases were treated list-wise and excluded from analyses ${ }^{(35,36)}$. As such, all reported analyses were conducted on valid cases only. All analyses were conducted using the statistical software package IBM SPSS Statistics 22.

The measure of SES used in the present study was the Index of Relative Socio-Economic Disadvantage. This index, which includes measures of income, education and occupational status, is part of the Australian Bureau of Statistics' Socio-Economic Indexes for Areas (SEIFA) classification $^{(37)}$. WA-specific quintiles were used in all SES analyses.

\section{Results}

Just over half ( $54 \%$ ) of the FOODcents courses run over the two-year period were evaluated ( $n$ 216), which represented the majority of courses attended by participants with literacy levels that were adequate for survey completion. Only those who completed both the pre- and post-course surveys were included in the study, resulting in usable survey responses from 927 participants. Of the 431 who could be contacted by email to request participation in the online follow-up survey, 114 responded (26\% response rate for the survey, representing $12 \%$ of the total evaluation sample). Valid data were collected from ninety-six participants.

Over the two-year evaluation period, the sessions were delivered by fifteen representatives from the three NGO. Average group size was eleven and average session duration was $1.5 \mathrm{~h}$. A large majority of the sample was female (76\%), reflecting the continuing role of women as primary caregivers in Australia ${ }^{(38)}$. Just over half (56\%) of the survey respondents reported being parents of children under 18 years of age. In terms of relative advantage, $42 \%$ of the survey respondents were classified as low SES according to the SEIFA rating of their suburb of residence ${ }^{(37)}$. A further $43 \%$ were classified as medium SES and $15 \%$ as high SES.

The data generated from the various data collection processes yielded information relating to participants' perceptions of the FOODcents course and any changes in their nutrition knowledge and dietary behaviours. The following sections outline the results relating to each of these outcomes. 


\section{Course perceptions}

As shown in Table 2, across the survey data obtained from both single- and multi-session courses there were very high levels of perceived usefulness, ease of understanding, anticipated implementation of concepts taught and intended positive word-of-mouth behaviours. There were no significant differences in these outcomes by participant SES.

Participants were asked to indicate their confidence in their ability to buy healthy foods within their budgets. Table 3 shows that participants' confidence increased significantly after exposure among those attending both types of courses. There were no significant differences by course type or SES in pre- to post-course change in this variable.

\section{Knowledge improvements}

The assessed knowledge improvements related to participants' ability to categorize foods by their healthiness, manage their food budgets, interpret food labels and understand the diet-disease link.

\section{Food categorization}

Within the healthy eating pyramid component of the FOODcents curriculum, participants are informed about which foods are allocated to the 'Eat Most', 'Eat Some' and 'Eat Least' categories of the pyramid. Changes in knowledge relating to food categorization across the six food groups represented in the healthy eating pyramid were assessed. As shown in Table 4, many of the improvements

Table 2 Positive perceptions of the course by course type in an evaluation of the FOODcents adult nutrition education programme, Western Australia, June 2012-May 2014

\begin{tabular}{|c|c|c|c|c|c|c|}
\hline \multirow[b]{2}{*}{ Question } & \multicolumn{2}{|c|}{$\begin{array}{c}\text { Multi- } \\
\text { session } \\
\text { courses }\end{array}$} & \multicolumn{2}{|c|}{$\begin{array}{l}\text { Single- } \\
\text { session } \\
\text { courses }\end{array}$} & \multicolumn{2}{|c|}{ Total } \\
\hline & $n \dagger$ & $\%$ & $n \dagger$ & $\%$ & $n \dagger$ & $\%$ \\
\hline How useful did you find this FOODcents course? (scale: 'very useful'/'not at all useful') & 576 & 94 & 264 & 92 & 840 & 94 \\
\hline How easy was it to understand the information provided? (scale: 'very easy'/'very hard') & 575 & 94 & 275 & 97 & 850 & 95 \\
\hline How likely is it that you will use at least some of the information provided? (scale: 'very likely'/'very unlikely') & 559 & 92 & 268 & 94 & 827 & 92 \\
\hline Would you recommend the FOODcents course to a friend? (scale: 'yes'/'no'/'maybe') & 505 & 94 & 166 & 90 & 671 & 93 \\
\hline
\end{tabular}

†Positive responses: 'very useful'/'useful'; 'very easy'/'easy'; 'very likely'/likely'; 'yes'.

Table 3 Confidence to purchase healthy foods on a budget $\dagger$ by course type in an evaluation of the FOODcents adult nutrition education programme, Western Australia, June 2012-May 2014

\begin{tabular}{|c|c|c|c|c|c|c|c|c|}
\hline \multirow[b]{2}{*}{ Course type } & \multirow[b]{2}{*}{$n$} & \multicolumn{3}{|c|}{ Pre-course } & \multicolumn{3}{|c|}{ Post-course } & \multirow[b]{2}{*}{ Significance } \\
\hline & & Mean & SD & $\% \ddagger$ & Mean & SD & $\% \ddagger$ & \\
\hline Multi-session & 577 & 2.34 & $1 \cdot 19$ & 56 & 1.76 & 0.93 & 80 & $<0.001$ \\
\hline Single-session & 278 & $2 \cdot 23$ & $1 \cdot 17$ & 60 & 1.69 & 0.85 & 83 & $<0.001$ \\
\hline Total/average & 855 & $2 \cdot 31$ & $1 \cdot 18$ & 57 & 1.74 & 0.90 & 81 & $<0.001$ \\
\hline
\end{tabular}

†ltem wording: 'How confident are you that you can buy healthy foods on a budget?' (scale: $1=$ 'very confident' to $5=$ 'very unsure').

$\ddagger$ Percentage reporting 'confident' or 'very confident'.

Table 4 Correct responses to selected knowledge items by course type in an evaluation of the FOODcents adult nutrition education programme, Western Australia, June 2012-May 2014

\begin{tabular}{|c|c|c|c|c|c|c|c|c|c|c|}
\hline & \multicolumn{5}{|c|}{ Single-session courses } & \multicolumn{5}{|c|}{ Multi-session courses } \\
\hline & \multicolumn{2}{|c|}{ Pre } & \multicolumn{2}{|c|}{ Post } & \multirow[b]{2}{*}{$P$ value } & \multicolumn{2}{|c|}{ Pre } & \multicolumn{2}{|c|}{ Post } & \multirow[b]{2}{*}{$P$ value } \\
\hline & $n$ & $\%$ & $n$ & $\%$ & & $n$ & $\%$ & $n$ & $\%$ & \\
\hline \multicolumn{11}{|l|}{ Correct classification of foods to healthy eating pyramid } \\
\hline \multicolumn{11}{|c|}{ Should you 'Eat Most', 'Eat Some' or 'Eat Least' of these foods each day? } \\
\hline Fruit & 80 & 60 & 112 & 86 & $<0.001$ & 183 & 55 & 234 & 77 & $<0.001$ \\
\hline Vegetables & 119 & 88 & 131 & 97 & 0.005 & 262 & 79 & 281 & 92 & $<0.001$ \\
\hline Dairy foods & 103 & 77 & 115 & 86 & 0.060 & 241 & 75 & 245 & 81 & 0.059 \\
\hline Breads and cereal & 23 & 17 & 83 & 62 & $<0.001$ & 82 & 25 & 162 & 54 & $<0.001$ \\
\hline Meat & 87 & 65 & 115 & 86 & $<0.001$ & 222 & 67 & 235 & 78 & 0.002 \\
\hline Extras (other foods) & 92 & 76 & 116 & 91 & 0.002 & 225 & 72 & 259 & 90 & $<0.001$ \\
\hline \multicolumn{11}{|l|}{ Correct responses to Nutrition Information Panel questions } \\
\hline What is the main ingredient in the product? & 61 & 68 & 71 & 80 & 0.068 & 160 & 65 & 193 & 77 & 0.004 \\
\hline In this product is there more sugar or strawberries? & 82 & 91 & 84 & 94 & 0.399 & 233 & 90 & 240 & 95 & 0.023 \\
\hline In $100 \mathrm{~g}$ of this product, how many grams of sugar are there? & 73 & 81 & 85 & 94 & 0.006 & 213 & 84 & 224 & 91 & 0.010 \\
\hline
\end{tabular}


in respondents' understanding of the pyramid groupings reached statistical significance across both course types.

Examination of differences in knowledge change by SES revealed a significant overall difference for meat $\left(\chi^{2}(2)=8 \cdot 91, P=0 \cdot 012, \Phi=0 \cdot 15\right)$ and extras $\left(\chi^{2}(2)=7 \cdot 68\right.$, $P=0.022, \quad \Phi=0 \cdot 14)$. Post hoc analyses revealed that low-SES participants were significantly more likely than midSES participants to improve their knowledge of the correct classification of meat $\left(\chi^{2}(1)=8.91, P=0.003, \quad \Phi=0 \cdot 16\right)$. Low-SES participants were significantly more likely than mid-SES $\left(\chi^{2}(1)=4 \cdot 08, \quad P=0.043, \quad \Phi=0 \cdot 11\right)$ and high-SES $\left(\chi^{2}(1)=6.89, P=0.009, \Phi=0.22\right)$ participants to improve their knowledge of the correct classification of extras.

\section{Budgeting}

The budgeting component of the FOODcents curriculum focuses on challenging participants' perceptions of the cost of healthy foods ${ }^{(24)}$. This approach reflects the recognized assumption that healthy foods are too expensive for those on limited budgets ${ }^{(39)}$. The costs of foods represented in each section of the healthy eating pyramid are compared during FOODcents courses, with real-life examples used to demonstrate that 'Eat Most' foods are the cheapest per kilogram, followed by 'Eat Some' and then 'Eat Least'.

Respondents were asked 'For a healthy diet, which group should we spend most of our food money on?', with response options of 'Eat Most (breads, cereals, fruit and vegetables)', 'Eat Some (meat and dairy foods)' and 'Eat Least (extra foods)'. Respondents were also asked 'How should different product prices be compared?', with response options of 'per serve', 'per kilogram' and 'per packet'. A further item asked participants to 'Please rank these breakfast cereals by value for money, from best (1) to worst (3)', with 'Weet-bix', 'Nutri-Grain' and 'Rolled Oats' presented as response options. Respondents' ability to correctly identify the food groups on which the greatest proportion of their budgets should be spent (i.e. the 'Eat Most' category) improved significantly post-attendance. In the pre-session survey, $80 \%$ made the correct allocation compared with $92 \%$ at the end of the course $\left(\chi^{2}(1)=18.98, P=0 \cdot 001, \Phi=0 \cdot 17\right)$. In addition, the ability to rank breakfast cereals by value for money improved significantly $\quad\left(57 \% \quad v . \quad 79 \%: \quad \chi^{2}(1)=33.99, \quad P<0.001\right.$, $\Phi=0 \cdot 23$ ), as did respondents' knowledge of how different product prices should be compared (i.e. price per kilo, $52 \%$ v. $\left.65 \%: \chi^{2}(1)=11.72, P=0.001, \Phi=0.13\right)$. Analyses conducted to investigate any differences in knowledge change by SES revealed no significant differences (correct identification of 'Eat Most' category: $\chi^{2}(2)=1 \cdot 14, P=0.566$, $\Phi=0.07$; price comparison: $\chi^{2}(2)=4.99, \quad P=0.082$, $\Phi=0 \cdot 14$; breakfast cereal ranking: $\chi^{2}(2)=3 \cdot 56, P=0 \cdot 168$, $\Phi=0 \cdot 12)$.

\section{Food label reading}

During FOODcents courses featuring a food label reading component, participants are informed that the ingredients list and Nutrition Information Panel on packaged foods are the most important predictors of a food's healthfulness. In the relevant survey items, respondents were exposed to a nutrition information panel for a fictional product and asked to report the main ingredient, state whether the product contained more of one ingredient relative to another, and report the amount of sugar per $100 \mathrm{~g}$. Pearson $\chi^{2}$ analyses revealed a higher proportion of correct responses in the post-session surveys across the three knowledge areas (Table 3). All improvements reached statistical significance in the multi-session courses. There were no significant differences by SES.

\section{Diet-disease link}

Table 5 shows the quantitative results for the improvements in relevant knowledge relating to specific diseases. A five-point Likert-type scale was used to assess participants' perceptions of the strength of the diet-disease link, with $1=$ 'very strong' and $5=$ 'very weak'. The consistent reduction in means demonstrates greater awareness of the links between diet/obesity and the nominated diseases, with many of the improvements reaching statistical significance.

Analyses conducted to examine whether the improvements in knowledge relating to the perceived link between diet/obesity and disease differed by SES found a significant difference between SES groups. Fisher's LSD post hoc tests revealed that those in the low-SES group demonstrated significantly greater change than those in both the mid-SES and high-SES groups across all the examined variables (Table 5).

\section{Reported behaviour change}

Of particular interest was whether participants were willing and able to implement their new knowledge. Assessed behaviour changes related to the reported consumption of a range of healthy and unhealthy foods. Table 6 shows changes in fruit, vegetable and fast-food consumption reported by participants attending the multi-session courses. Equivalent data could not be collected from participants attending single-session courses because these respondents had not had an opportunity to implement new knowledge at the time of completing the post-session survey (i.e. the pre and post instruments were administered in the same session).

To examine whether pre- to post-course changes in dietary behaviours differed by SES, a series of one-way ANOVA was conducted (Table 6). Modest but significant differences were found, with Fisher's LSD post hoc tests revealing that those in the low-SES group reported significantly greater change than those in the mid-SES group for servings of fruit consumed per day $(P=0.032)$. Those in the low-SES group also reported significantly greater change than those in the mid-SES group for number of days that fast food was consumed in the previous week $(P=0.006)$. 

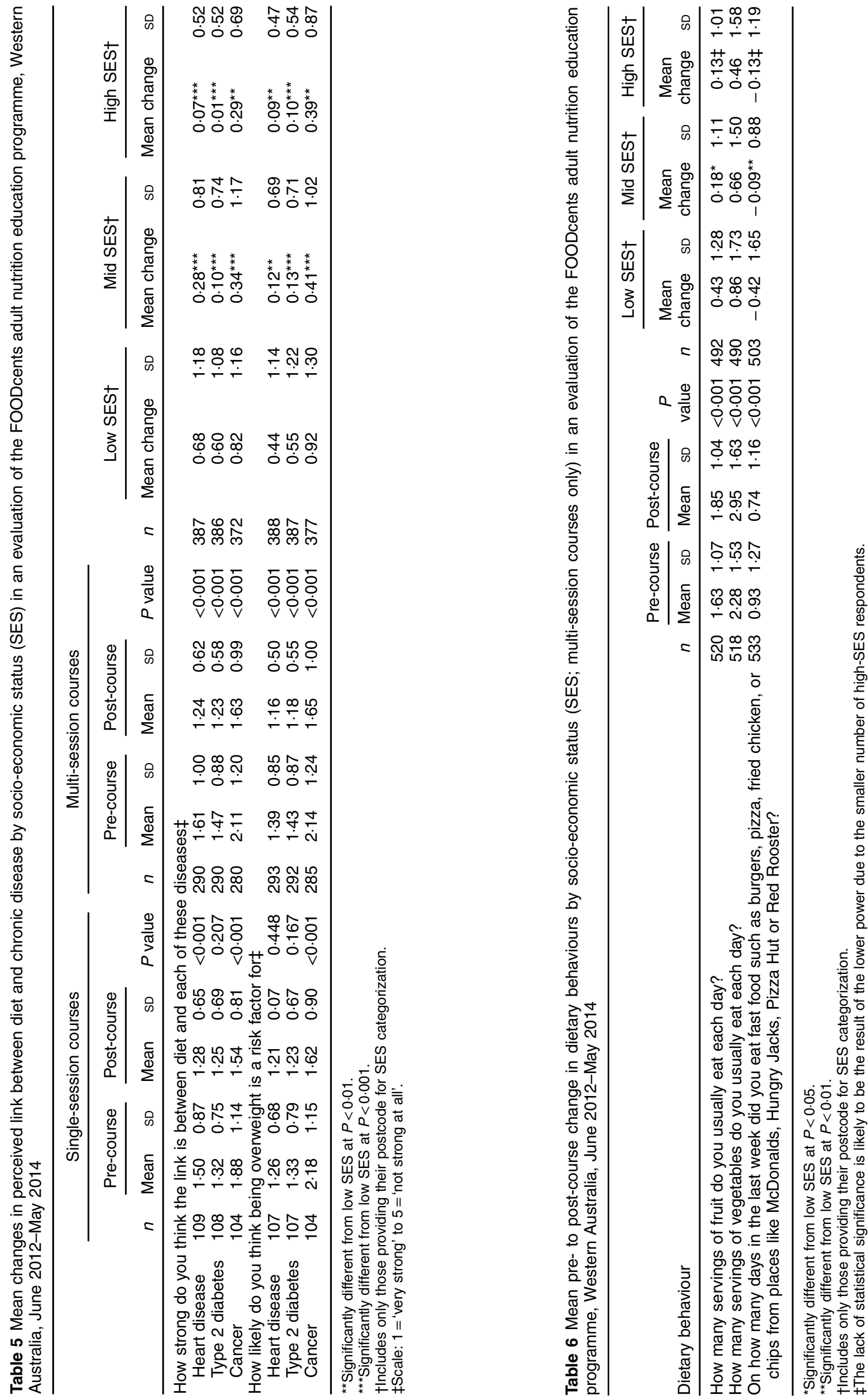
Table 7 Reported mean change in eating, shopping and food preparation behaviours (online follow-up survey, $n$ 96) in an evaluation of the FOODcents adult nutrition education programme, Western Australia, June 2012-May 2014

\begin{tabular}{|c|c|c|c|c|c|}
\hline \multirow[b]{2}{*}{ Behaviours $†$} & \multicolumn{2}{|c|}{ Pre } & \multicolumn{2}{|c|}{ Postł } & \multirow[b]{2}{*}{$P$ value } \\
\hline & Mean & SD & Mean & SD & \\
\hline Choose wholemeal/rye bread & 1.99 & 1.04 & 1.66 & 0.86 & $<0.001$ \\
\hline Eat legumes or beans & 2.69 & 0.81 & $2 \cdot 20$ & 0.82 & $<0.001$ \\
\hline Drink cordial or cool drinks (including diet versions) & 2.79 & 0.89 & $3 \cdot 24$ & 0.79 & $<0.001$ \\
\hline Eat pre-packaged biscuits or cakes & $2 \cdot 71$ & 0.74 & $3 \cdot 10$ & 0.57 & $<0.001$ \\
\hline Look for low-salt varieties & 2.90 & 1.02 & 1.94 & 0.93 & $<0.001$ \\
\hline Change recipes to make them healthier & $2 \cdot 69$ & 0.99 & $1 \cdot 77$ & 0.64 & $<0.001$ \\
\hline Read the Nutrition Information Panel & $2 \cdot 79$ & $1 \cdot 15$ & 1.69 & 0.72 & $<0.001$ \\
\hline Read the ingredients list & 2.68 & 1.07 & 1.64 & 0.65 & $<0.001$ \\
\hline Look at price per kilo & $2 \cdot 41$ & 1.08 & 1.60 & 0.77 & $<0.001$ \\
\hline
\end{tabular}

†ltem wording: 'Please tell us to what extent you did the following things before/after the course?' (response options: $1=$ 'always', 2 = 'often', $3=$ 'sometimes', $4=$ 'never').

$\ddagger$ Approximately six weeks after course attendance.

Table 7 shows the changes in other dietary-related behaviours reported by respondents to the online postsession survey. Small cell sizes precluded analysis by SES. Statistically significant improvements were observed for all behaviours.

\section{Discussion}

An overarching principle of the WHO's Global Action Plan for the Prevention and Control of NCDs ${ }^{(3)}$ is that governments should focus their disease-prevention efforts on programmes that are evidence-based. However, in the context of nutrition education there is a lack of information available relating to the types of programmes and interventions that are delivered around the world and their effectiveness $^{(1)}$. In particular, there is a lack of information relating to differential programme outcomes according to $\mathrm{SES}^{(10)}$. The aim of the present study was to evaluate the ability of the FOODcents nutrition education programme to improve nutrition knowledge and facilitate behaviour change, especially among low-SES participants. The results provide information of use to policy makers in their decision making relating to the allocation of scarce resources among various forms of obesity-prevention interventions.

The FOODcents evaluation outcomes indicated significant improvements in nutrition-related knowledge among participants. After exposure to the course, participants demonstrated a greater ability to: (i) categorize foods according to the quantities that should be consumed and the proportion of the food budget that should be allocated to them; (ii) correctly interpret nutrition labels on food products; and (iii) appreciate the link between diet/obesity and a range of diseases. Improvements in the latter were especially pronounced among low-SES participants. The significantly greater improvements in knowledge relating to the classification of meat and extra foods among low-SES participants is important in the context of
lower-SES Australians being more likely to consume excessive quantities of these products ${ }^{(40,41)}$.

As noted by Contento et al. ${ }^{(34)}$, behaviour change is an outcome of primary importance in nutrition education interventions. The results of the present study indicate that the information and skills taught during FOODcents courses are also translated into participants' food-related behaviours. In particular, improvements in fruit and vegetable consumption and reductions in fast-food consumption were reported, especially among low-SES participants. In addition, the results of the online survey conducted several weeks after course completion suggest that dietary changes may persist beyond the period of course attendance.

Overall, the results indicate that FOODcents is an effective nutrition education programme that may be especially advantageous in terms of its ability to cater for the needs of lower-SES individuals and therefore assist in addressing existing inequalities in nutrition knowledge ${ }^{(42)}$. This outcome is important in the context of a recent review which found that nutrition education programmes are typically very limited in their ability to improve outcomes for low-SES individuals ${ }^{(10)}$. The apparent utility of the FOODcents face-to-face method of information provision and the inclusion of a range of in-class activities specifically designed to teach relevant skills is consistent with previous research that has highlighted the importance of human interaction in conveying health-related knowledge to the disadvantaged ${ }^{(43)}$. It is also consistent with the positive outcomes reported from the EFNEP, which uses a similar face-to-face approach and is one of the other few long-standing nutrition education programmes to be evaluated over time and to demonstrate both immediate and prolonged benefits to participants ${ }^{(13-16)}$.

Of note is that FOODcents courses delivered over single sessions were found to be effective in terms of knowledge and confidence improvements. These courses were also perceived as very useful and likely to influence future behaviours. Although it was not possible to assess direct 
behaviour changes resulting from attendance in the single sessions, these outcomes indicate that nutrition education programmes can offer a range of course types to meet the time constraints and duration preferences of different groups of participants. Providing multiple delivery options is likely to make nutrition education programmes accessible to a broader range of potential participants and increase cost-effectiveness by permitting those whose needs can be met by shorter courses to select these options rather than the longer-duration (and therefore more costly) alternatives.

Although the improvements in knowledge identified in the present evaluation are robust due to the pre-post method of assessment, major limitations were the inability to administer the instruments to low-literacy participants and a reliance on self-report data relating to behaviour change. These are standard limitations in research examining behaviours among disadvantaged individuals that are largely enacted within the family home and hence are not readily observable. The gold standard for assessing behaviour change in this domain is the collection of biomedical data to assess dietary change and changes in body mass and physiological markers ${ }^{(10)}$. This is an important consideration for future studies that attempt to provide concrete evidence of the efficacy of education and skills-based approaches in enhancing nutrition at the population level. Further, the effects of the course may decay over time or, alternatively, attendance may act as a catalyst that encourages incremental information gathering by participants, thereby having positive ongoing effects on their nutrition knowledge and behaviours. Future studies could include follow-up data collection episodes to assess longer-term outcomes to determine whether booster sessions are needed.

As noted above, an additional limitation was the use of course instructors to administer the in-session surveys. However, the use of an online follow-up survey prevented sole reliance on data collected by instructors. The results obtained from the different surveys were consistent, indicating that the nature of in-session survey administration did not overly contaminate the study outcomes.

Further limitations include the lack of a control group and the probability that those attending FOODcents courses are more receptive to acquiring nutrition information and implementing nutrition-related behaviour change than individuals who do not elect to attend such courses. In line with the transtheoretical model of the stages of change ${ }^{(44)}$, course attendees are likely to be in the contemplation or action phases of dietary change, and hence self-select to expose themselves to FOODcents. As a result, the demonstrated increases in knowledge and reported behaviour change reflect outcomes associated with this heightened level of interest and are unlikely to be replicated among other members of the general public who are in the pre-contemplation stage. FOODcents addresses this issue through dissemination of promotional materials via three different NGO that offer assistance to a broad range of client groups that are typically characterized by financial disadvantage and/or diagnosed health problems. These groups are likely to be motivated to attend courses that can assist them to better manage their finances and/or their diets. In addition to promotion via the three NGO, a website provides information to those searching the Internet for nutrition education programmes available in Western Australia (www.foodcentsprogram. com.au). Through these avenues, the programme is actively promoted to those of greatest need who may be interested in participating.

Given that poor diet is a factor contributing to the differential in weight status between low- and high-SES individuals $^{(45)}$, it is important to address dietary issues as part of comprehensive efforts to reduce health inequalities. While recognizing that individual-level education and skills-based programmes need to be complemented with structural-level initiatives ${ }^{(2,10,46)}$, programmes such as FOODcents have a role to play in reducing inequalities by providing the disadvantaged with specific food selection and preparation skills, thereby enabling them to make meaningful changes to their diets.

\section{Acknowledgements}

Acknowledgements: The authors thank Australian Red Cross Red Cross, Foodbank WA, Nicole Biagioni and Melanie Pescud for their assistance with data collection. Financial support: FOODcents is funded by the Western Australian Department of Health. Conflict of interest: The Cancer Council Western Australia is funded by the Western Australian Department of Health to deliver FOODcents. S.M. and I.S.P. are employed by the Cancer Council Western Australia. Authorship: S.P., S.M. and I.S.P. conceptualized the study design. S.M. and S.P. managed data collection. M.J. and S.P. performed the data analysis. All authors contributed to the preparation of the manuscript. Ethics of buman subject participation: The protocol received approval from the University of Western Australia Human Ethics Committee.

\section{References}

1. Hawkes C, Jewell J \& Allen K (2013) A food policy package for healthy diets and the prevention of obesity and dietrelated non-communicable diseases: the NOURISHING framework. Obes Rev 14, 159-168.

2. Zhang Q, Liu S, Liu R et al. (2014) Food policy approaches to obesity prevention: an international perspective. Curr Obes Rep 3, 171-182.

3. World Health Organization (2013) Global Action Plan for the Prevention and Control of NCDs 2013-2020. Geneva: WHO.

4. Sacks G, Swinburn B \& Lawrence M (2009) Obesity policy action framework and analysis grids for a comprehensive policy approach to reducing obesity. Obes Rev 10, 76-86. 
5. Rutter H (2011) Where next for obesity? Lancet $\mathbf{3 7 8}$, 746-747.

6. Koszewski W, Sehi N, Behrends D et al. (2011) The impact of SNAP-ED and EFNEP on program graduates 6 months after graduation. $J$ Extension 49, issue 5, available at http://www.joe.org/joe/2011october/rb6.php

7. Rustad C \& Smith C (2012) A short-term intervention improves nutrition attitudes in low-income women through nutrition education relating to financial savvy. J Hunger Environ Nutr 7, 205-223.

8. Australian Bureau of Statistics (2013) Profiles of Health, Australia, 2011-13. Canberra: ABS.

9. Australian Institute of Health and Welfare (2012) Australia's Health 2012. Australia's Health no. 13. Canberra: AIHW.

10. Beauchamp A, Backholer K, Magliano D et al. (2014) The effect of obesity prevention interventions according to socioeconomic position: a systematic review. Obes Rev 15, 541-554.

11. Cullen KW, Smalling AL, Thompson D et al. (2009) Creating healthful home food environments: results of a study with participants in the expanded food and nutrition education program. J Nutr Educ Behav 41, 380-388.

12. Rajgopal R, Cox RH, Lambur M et al. (2002) Cost-benefit analysis indicates the positive economic benefits of the Expanded Food and Nutrition Education Program related to chronic disease prevention. J Nutr Educ Behav 34, 26-37.

13. Amstutz MK \& Dixon DL (1986) Dietary changes resulting from the Expanded Food and Nutrition Education Program. $J$ Nutr Educ 18, 55-60.

14. Arnold CG \& Sobal J (2000) Food practices and nutrition knowledge after graduation from the Expanded Food and Nutrition Education Program (EFNEP). J Nutr Educ 32, 130-138.

15. Brink MS \& Sobal J (1994) Retention of nutrition knowledge and practices among adult EFNEP participants. J Nutr Educ 26, 74-78.

16. Dollahite JS, Pijai EI, Scott-Pierce M et al. (2014) A randomized controlled trial of a community-based nutrition education program for low-income parents. J Nutr Educ Behav 46, 102-109.

17. Burney J \& Haughton B (2002) EFNEP: a nutrition education program that demonstrates cost-benefit. J Am Diet Assoc 102, 39-45.

18. Dollahite J, Kenkel D \& Thompson CS (2008) An economic evaluation of the expanded food and nutrition education program. J Nutr Educ Behav 40, 134-143.

19. Anderson JV, Bybee DI, Brown RM et al. (2001) 5 a day fruit and vegetable intervention improves consumption in a low income population. J Am Diet Assoc 101, 195-202.

20. Devine CM, Farrell TJ \& Hartman R (2005) Sisters in health: experiential program emphasizing social interaction increases fruit and vegetable intake among lowincome adults. J Nutr Educ Behav 37, 265-270.

21. Havas S, Anliker J, Greenberg D et al. (2003) Final results of the Maryland WIC food for life program. Prev Med 37, 406-416.

22. Foley RM \& Pollard CM (1998) Food Cent\$ - implementing and evaluating a nutrition education project focusing on value for money. Aust N Z J Public Health 22, 494-501.

23. Foley RM (1998) The Food Cent\$ project: a practical application of behaviour change theory. Aust J Nutr Diet $\mathbf{5 5}$, 33-35.

24. Foley RM, Pollard CM \& McGuiness DJ (1997) Food Cent\$ achieving a balanced diet on a limited food budget. Aust J Nutr Diet 54, 167-172.

25. Ball K, Crawford D \& Mishra G (2006) Socio-economic inequalities in women's fruit and vegetable intakes: a multilevel study of individual, social and environmental mediators. Public Health Nutr 9, 623-630.

26. Miura K, Giskes K \& Turrell G (2011) Socio-economic differences in takeaway food consumption among adults. Public Health Nutr 15, 218-226.
27. Thornton LE, Bentley RJ \& Kavanagh AM (2011) Individual and area-level socioeconomic associations with fast food purchasing. J Epidemiol Community Health 65, 873-880.

28. Williams L, Ball K \& Crawford D (2010) Why do some socioeconomically disadvantaged women eat better than others? An investigation of the personal, social and environmental correlates of fruit and vegetable consumption. Appetite 55, 441-446.

29. Basu S, McKee M, Galea G et al. (2013) Relationship of soft drink consumption to global overweight, obesity, and diabetes: a cross-national analysis of 75 countries. Am J Public Health 103, 2071-2077.

30. World Health Organization \& Food and Agriculture Organization of the United Nations (2003) Diet, Nutrition and the Prevention of Chronic Diseases. Joint WHO/FAO Expert Consultation. WHO Technical Report Series no. 916. Geneva: WHO.

31. Green LW, Glanz K, Hochbaum GM et al. (1994) Can we build on, or must we replace, the theories and models in health education? Health Educ Res 9, 397-404.

32. Huye HF, Connell CL, Crook LB et al. (2014) Using the RE-AIM framework in formative evaluation and program planning for a nutrition intervention in the lower Mississippi Delta. J Nutr Educ Behav 46, 34-42.

33. Contento I (2008) Review of nutrition education research in the Journal of Nutrition Education and Behavior, 1998 to 2007. J Nutr Educ Behav 40, 331-340.

34. Contento IR, Randell JS \& Basch CE (2002) Review and analysis of evaluation measures used in nutrition education intervention research. J Nutr Educ Behav 34, 2-25.

35. Cameron AC \& Trivedi PK (2005) Microeconometrics: Methods and Applications. Cambridge: Cambridge University Press.

36. Graham JW (2009) Missing data analysis: making it work in the real world. Annu Rev Psychol 60, 549-576.

37. Australian Bureau of Statistics (2013) Socio-Economic Indexes for Areas (SEIFA), Data Cube Only, 2011. Canberra: ABS.

38. Australian Bureau of Statistics (2009) Australian Social Trends 2009. Canberra: ABS

39. Williams LK, Abbott G, Thornton LE et al. (2014) Improving perceptions of healthy food affordability: results from a pilot intervention. Int J Behav Nutr Phys Act 11, 33.

40. Mishra G, Ball K, Arbuckle J et al. (2002) Dietary patterns of Australian adults and their association with socioeconomic status: results from the 1995 National Nutrition Survey. Eur J Clin Nutr 56, 687-693.

41. Zarnowiecki DM, Dollman J \& Parletta N (2014) Associations between predictors of children's dietary intake and socioeconomic position: a systematic review of the literature. Obes Rev 15, 375-391.

42. Hendrie GA, Coveney J \& Cox D (2008) Exploring nutrition knowledge and the demographic variation in knowledge levels in an Australian community sample. Public Health Nutr 11, 1365-1371.

43. Albright CL, Bruce B, Howard Pitney B et al. (1997) Development of a curriculum to lower dietary fat intake in a multiethnic population with low literacy skills. J Nutr Educ 29, 215-223.

44. Prochaska JO \& Velicer WF (1997) The transtheoretical model of health behavior change. Am J Health Promot 12, $38-48$.

45. Gearon E, Backholer K, Hodge A et al. (2013) The mediating role of dietary factors and leisure time physical activity on socioeconomic inequalities in body mass index among Australian adults. BMC Public Health 13, 1214.

46. Swinburn B, Sacks G, Vandevijvere S et al. (2013) INFORMAS (International Network for Food and Obesity/noncommunicable diseases Research, Monitoring and Action Support): overview and key principles. Obes Rev 14, 1-12. 